Bull. Chem. Soc. Ethiop. 2020, 34(3), 613-623.

ISSN 1011-3924

(C) 2020 Chemical Society of Ethiopia and The Authors

Printed in Ethiopia

DOI: https://dx.doi.org/10.4314/bcse.v34i3.16

\title{
INTERACTIONS MECHANISM OF COMMONLY USED DRUGS FOR THE TREATMENT OF COVID-19
}

\author{
Sefa Celik ${ }^{1 *}$, A. Demet Demirag ${ }^{2}$, Aysen E. Ozel $^{1}$ and Sevim Akyuz ${ }^{3}$ \\ ${ }^{1}$ Physics Department, Science Faculty, Istanbul University, Vezneciler, 34134, Istanbul, Turkey \\ ${ }^{2}$ Institute of Graduate Studies in Sciences, Istanbul University, 34452, Istanbul, Turkey \\ ${ }^{3}$ Physics Department, Science and Letters Faculty, Istanbul Kultur University, Atakoy Campus, \\ Bakirkoy 34156, Istanbul, Turkey
}

(Received July 31, 2020; Revised December 21, 2020; Accepted December 23, 2020)

\begin{abstract}
In this study conformation analysis of seven drugs commonly used in the treatment of COVID-19 was performed. The most stable conformers of the drug molecules were used as initial data for docking analysis. Using the Cavityplus program, the probable most active binding sites of both apo and holo forms of COVID-19 main protease enzyme $\left(\mathrm{M}^{\mathrm{pro}}\right)$ and spike glycoprotein of SARSCoV-2 receptors were determined. The interaction mechanisms of the 7 FDA approved drugs (arbidol, colchicine, dexamethasone, favipiravir, galidesivir, hydroxychloroquine, remdesivir) were examined using the AutoDock Vina program. The six of the seven drugs were found to be more stable in binding to apo form of COVID-19 $\mathrm{M}^{\mathrm{pro}}$ and spike glycoprotein. Moreover, a set of molecular mechanics (MM) Poisson-Boltzmann (PB) surface area (SA) calculations on the investigated drugsprotein systems were performed and the estimated binding free energy of remdesivir and the apo form of $\mathrm{M}^{\text {pro }}$ system was found to be the best. The interaction results of FDA drugs with the apo form of COVID-19 $\mathrm{M}^{\text {pro }}$ and spike glycoprotein can play an important role for the treatment of COVID-19.
\end{abstract}

KEY WORDS: COVID-19, Drugs, Molecular modelling, Conformational analysis, Molecular docking

\section{INTRODUCTION}

Corona viruses belong to the family of Coronaviridae, a family of enveloped-single strand positive RNA viruses. The Coronaviridae family is divided into four types $(\alpha, \beta, \gamma$ and $\delta)$ [1]. The corona viruses of the alpha and $\beta$ strains usually infect mammals and humans, while the species $\gamma$ and $\delta$ infect birds. This specification was made according to the phylogenetic analysis of corona viruses and genome structure [2]. Corona virus SARS-CoV-2 (virus that causes COVID-19) is a new corona virus of the genus $\beta[2,3]$. The novel corona virus is highly homologous to the known SARS-CoV corona virus that caused an outbreak of severe acute respiratory syndrome (SARS) in 2000-2004, however it is not the same virus. There are currently no vaccines and/or specific therapeutic drugs that target SARS-CoV-2. Until we had specific vaccines or therapeutic drugs targeting SARS-CoV-2, FDA-approved "restructured" drugs would be used to treat patients with COVID-19. [4-6]. The protein called angiotensin converting enzyme 2 or ACE2 "receptor" is thought to provide the entry point for SARS-CoV-2 to bind and infect a wide variety of human cells, as like as SARS CoV.

FDA approved drugs, chloroquine (CQ), hydroxychloroquine (HCQ), remdesivir (RDV) and arbidol (USA) appear as promising antivirals to fight COVID-19. In this study molecular docking of the FDA approved drugs with COVID-19 $\mathrm{M}^{\text {pro }}$ were investigated. The hypothesis behind molecular docking studies is to identify the binding affinities of these drugs and identify key amino acid residues that play an important role in their mechanism of action.

In this study the interaction mechanisms of the 7 FDA approved drugs were investigated by docking of drugs with COVID-19 $\mathrm{M}^{\text {pro }}$ and spike glycoprotein. The docked drugs were hydroxychloroquine, remdesivir, arbidol, favipiravir, colchicine, galidesivir and dexamethasone.

*Corresponding author. E-mail: scelik@istanbul.edu.tr

This work is licensed under the Creative Commons Attribution 4.0 International License 
The results of trials and clinical studies on these drugs were summarized by Mohapatra et al. in 2020 [7].

The spike protein (S protein) of SARS-CoV has very important roles in viral infection and pathogenesis [1]. The main protease $\left(\mathrm{M}^{\mathrm{Pro}}\right)$ of SARS-CoV-2 is an enzyme essential for virus replication through viral proteolytic activity and subsequent generation of infectious virus particles. [8]. The SARS-CoV-2 $\mathrm{M}^{\text {Pro }}$ active site has two conformational stages: Apo (closed conformation) and holo (open conformation) stages [8].

In a study performed by Amin and Abbas [9], the in-silico interactions of chloroquine and hydroxychloroquine with the $\mathrm{N}$ terminal domain (NTD) of nucleocapsid protein (N protein) (NTD-N-protein) of SARS-CoV-2 were investigated and it was reported that these drugs bind efficiently to the active sites of the NTD-N-protein and reduce the efficacy.

In a study conducted by Rachakulla and Rachalulla [10], the in silico docking study was performed to reveal the potential bond affinity and binding interactions of dexamethasone remdesivir, hydroxyquinoline, favipiravir against COVID-19 $\mathrm{M}^{\text {pro }}$. It was found that dexamethasone, approved by the FDA for other medical purposes, has a high potential bond affinity and binding interactions against the SARS-CoV-2 protease compared to drugs currently used for COVID-19 treatment. However, it was noted that further clinical trials were needed to recommend as alternative medical treatments for COVID-19 [10].

Khan and Htar compared the binding affinities of the remdesivirin and dexamethasone for the SARS-COV-2 $\mathrm{M}^{\text {pro }}$ to find out the most preventive potential against COVID-19 [11]. Dexamethasone was found to bind with a high affinity to the same sites of the SAR-COV-2 $\mathrm{M}^{\text {pro }}$ better than remdesivir, due to having more hydrogen bonds than remdesivir antiviral drug.

In the study of Blaising et al., the physicochemical properties, pharmacokinetics, toxicity and molecular mechanisms of the arbidol drug, were investigated and predicted its possibility and suitability of a broad spectrum antiviral. It was thought that the interactions of arbidol with membranes and aromatic amino acids in proteins could be at the center of broad spectrum antiviral activity [12].

In this study, conformational analyzes of hydroxychloroquine, dexamethasone, favipiravir, arbidol, galidesivir, colchicine, remdesivir molecules were carried out to examine the energically possible conformers and to reveal their stability. In order to understand the biological activity and mechanism of these molecules against COVID-19 $\mathrm{M}^{\text {pro }}$, molecular docking study was carried out with apo and holo forms of COVID-19 $\mathrm{M}^{\text {pro }}$ and spike glycoprotein. The drugs were sorted on the basis of binding strength.

\section{METHODS AND CALCULATIONS}

Conformation analysis and optimized geometries of the seven molecules examined (hydroxychloroquine, dexamethasone, favipiravir, arbidol, galidesivir, colchicine, remdesivir). The analysis was performed using the Spartan06 program [13] using the AM1 semiempirical quantum mechanical method [14].

The potential binding sites on the surface of the receptors were determined using the Cavityplus program [15]. Molecular docking studies were performed on the identified active sites [16], using AutoDock-Vina software. The binding free energies of the most stable ligandprotein systems that determined by molecular docking analysis, were calculated by the programs developed by Wang [17] and the ACFIS 2.0 web server [18-21].

\section{RESULTS AND DISCUSSION}

The spike protein, the main antigenic component responsible for inducing host immune responses, neutralizing antibodies, and protective immunity against virus infection, is a 
structural protein of SARS-CoV. Therefore, spike protein is chosen as the target for the presence of corona virus vaccine and development of anti-viral drugs [22]. The $\mathrm{M}^{\text {pro }}$ is a vital role in polyprotein processing and virus maturation, for this reason COVID-19 $\mathrm{M}^{\text {pro }}$ is an attractive drug target for antiviral drug design toward COVID-19 treatment. Cavities of apo and holo forms of COVID-19 $\mathrm{M}^{\text {pro }}$ and spike glycoprotein of SARSCoV-2 receptors were determined using the Cavityplus program [15]. Among these cavities, the cavities with the highest probability of binding molecules were determined according to drug score and Pred Max $\mathrm{pK}_{\mathrm{d}}$ value. Respectively three and one druggable cavities were determined according to drug score value in apo form of COVID-19 $\mathrm{M}^{\text {pro }}$ and spike glycoprotein, and also one cavity was determined according to Pred Max $\mathrm{pK}_{\mathrm{d}}$ value in holo form of COVID-19 $\mathrm{M}^{\mathrm{pro}}$. Using the AutoDock Vina program [16], the molecules were docked to the active sites which are druggable cavities. The crystal structures of spike glycoprotein (PDB ID: 6VXX), apo form of COVID-19 $\mathrm{M}^{\text {pro }}$ (PDB ID: 6M03) and holo form of COVID-19 $\mathrm{M}^{\text {pro }}$ (PDB ID: 6LU7) were obtained from the protein database [23-25]. The docking for molecules was adapted by removing the water molecule from the receptors and adding polar hydrogens. The active sites of the apo and holo forms of the COVID-19 $\mathrm{M}^{\text {pro }}$ and the spike glycoprotein of SARSCoV-2 were defined in the grid size of $40 \AA \times 40 \AA \times 40 \AA$.

In Table 1 , the binding sites, binding energies of apo and holo forms COVID-19 $\mathrm{M}^{\text {pro }}$ and spike glycoprotein protein with drugs are given. Figures 1-7 presents the interactions between target proteins and drugs.

The interactions between the arbidol molecule and the apo form of COVID-19 $\mathrm{M}^{\text {pro }}$ are as follows (see Figure 1): $3.98 \AA$ long alkyl interaction with the Val104 amino acid; $2.59 \AA$ long hydrogen bond interaction between arbidol and the Gln110 amino acid; $3.33 \AA$ long hydrogen bond interaction with the Asn151 amino acid; $3.94 \AA$ long pi-sigma interaction with the Phe294 amino acid; 3.99 A long pi-sigma interaction with the Val303 amino acid; 5.03 A long pi-sulfur interaction with the Phe305 amino acid. Our results are in accord with previous findings. Recently, Sing and Flores [26] investigated the interactions between apo form of $\mathrm{M}^{\mathrm{pro}}$ (PDB ID: $6 \mathrm{M} 03$ ) and some molecules that could be used as therapeutics against COVID-19 disease including ramipril benzyl ester, propafenone dimer, lariciresinol, citrusinol, segatalin, cinobufagin and vitisnol C. Their results were in accord with our findings [26]. The molecular docking analysis performed by Sing and Flores [26] revealed that ramipril benzyl ester interacts with Asn151, Phe294 and Val 303 amino acid residues of the target protein 6M03. Moreover the results showed that, propafenone dimer interacts with Gln110, Phe294, and Phe305, citrusinol molecule interacts with Asn151 and Gln110 residues. These results are in accord with our findings. Our docking simulations showed that arbitol molecule is involved in interaction with Gln110, Asn151, Phe294, Val303 and Phe305 amino acid residues of $\mathrm{M}^{\text {pro }}$ target protein. The docking outcomes suggest that arbitol binds to the same amino acid residues as the other molecules [26], which are known to be effective against COVID-19. Arbitol showed better binding affinity for the apo form of $\mathrm{M}^{\text {pro }}(-6.5 \mathrm{kcal} / \mathrm{mol})$ then the holo form $(-6.0 \mathrm{kcal} / \mathrm{mol})$.

Colchicine showed better binding affinity for the SARS-COV2-spike glycoprotein (-6.9 $\mathrm{kcal} / \mathrm{mol})$ then the apo form of $\mathrm{M}^{\mathrm{pro}}(-6.8 \mathrm{kcal} / \mathrm{mol})$ (see Figure 2). Colchicine interacted with Arg466, Asp467 and Ile468 residues of the spike glycoprotein. In the study on the molecular interaction docking between synthetic peptides and SARS-CoV-2 spike glycoprotein [27] the presence of an interaction between Mo-CBP3-PepII peptide and through Arg466 residue of spike glycoprotein was shown. TheArg466 is the same amino acid residue of spike glycoprotein that the colchicine molecule interacts.

As a result of molecular docking analysis of dexamethasone with the apo form of COVID$19 \mathrm{M}^{\mathrm{pro}}$, the following interactions are yielded (see Figure 3): $5.01 \AA$ long pi-alkyl interaction with Phe8 residue; $3.83 \AA$ long Alkyl interaction with Arg298 residue; $4.71 \AA$ long alkyl interaction with Val303 residue and 4.57 and $5.47 \AA$ long pi-alkyl interactions with Phe 305 residue. Comparison of our results with those of ramipril benzyl ester coupled with 6M03 [26] 
showed that the amino acids with which the dexamethasone molecule interacted were the same as the ramipril benzyl ester molecule, indicating that the binding active site in the apo form was the same. The dexamethasone showed a better binding affinity for the apo form of $\mathrm{M}^{\text {pro }}(-8.6$ $\mathrm{kcal} / \mathrm{mol})$ than the holo form $(-7.8 \mathrm{kcal} / \mathrm{mol})$ and the spike glycoprotein $(-7.4 \mathrm{kcal} / \mathrm{mol})$.

Table 1 . The binding affinity values of the title compounds predicted by Autodock Vina.

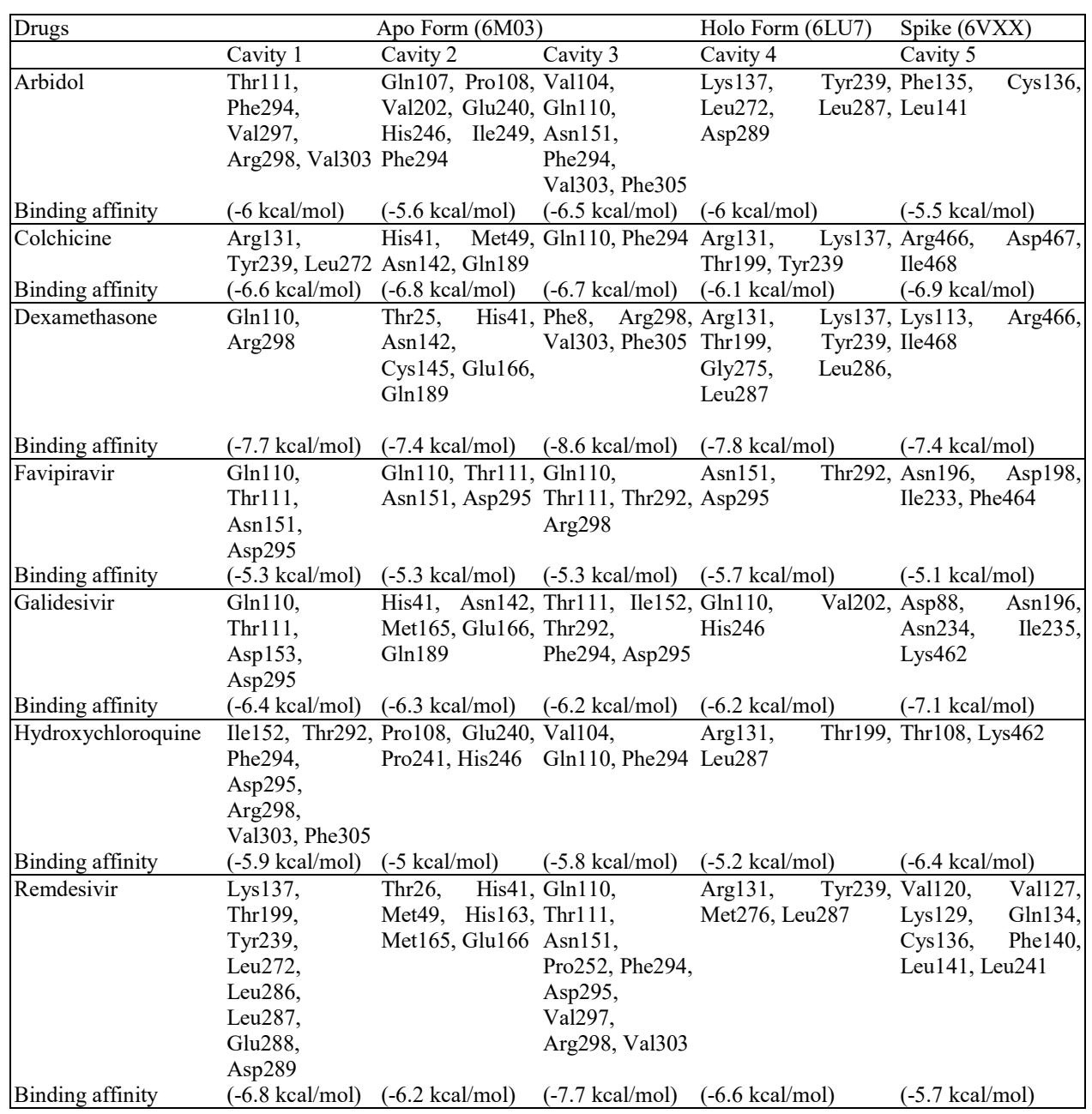



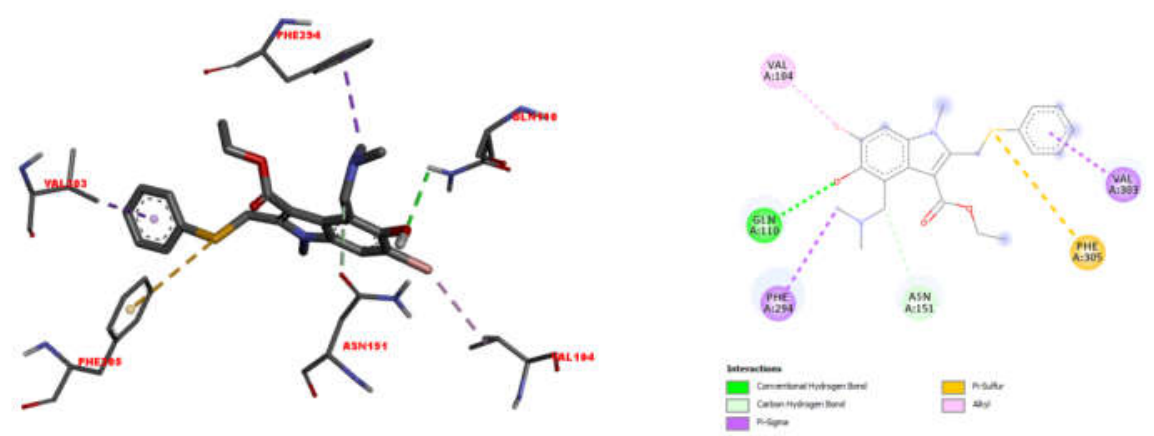

Figure 1. 2-D molecular docked structure of arbidol with the apo form of COVID-19 $\mathrm{M}^{\text {pro }}$. Doted lines present the interactions of arbidol with apo form (cavity3; binding affinity, $-6.5 \mathrm{kcal} / \mathrm{mol})$.
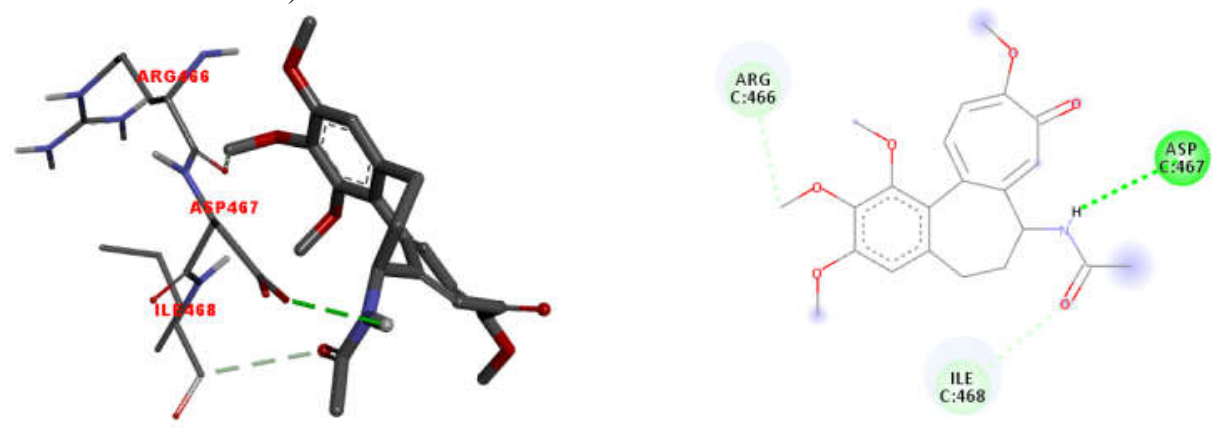

Interactions

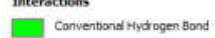

Figure 2. 2-D molecular docked structure of colchicine with Spike glycoprotein. Doted lines present the interactions of colchicines with spike glycoprotein (cavity5; binding affinity, $-6.9 \mathrm{kcal} / \mathrm{mol}$ ).
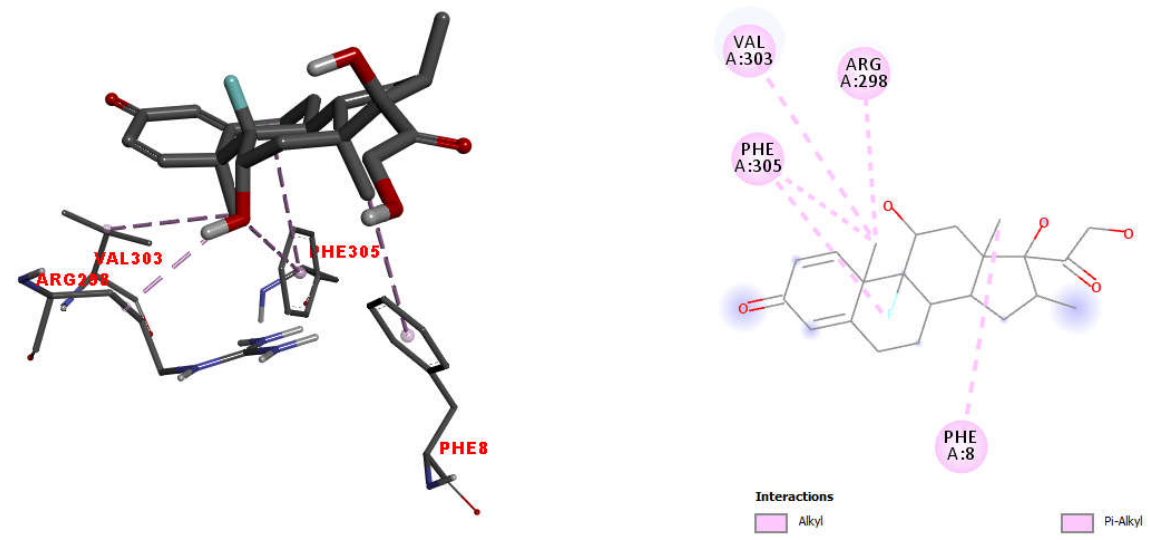

Figure 3. 2-D molecular docked structure of dexamethasone with the apo form of COVID-19 $\mathrm{M}^{\mathrm{pro}}$. Doted lines present the interactions of dexamethasone with apo form (cavity3; binding affinity, $-8.6 \mathrm{kcal} / \mathrm{mol})$.

Bull. Chem. Soc. Ethiop. 2020, 34(3) 

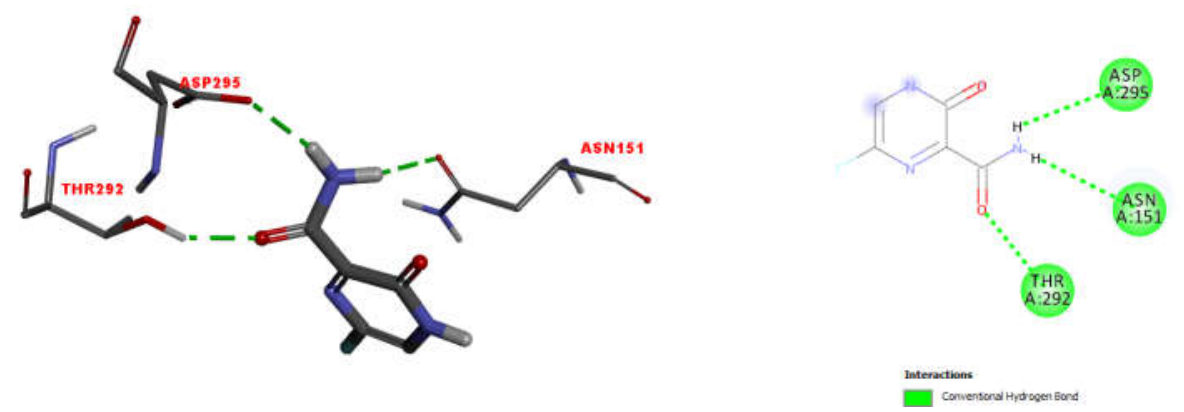

Figure 4. 2-D Molecular docked structure of favipiravir with the holo form of COVID-19 $\mathrm{M}^{\text {pro }}$. Doted lines present the interactions of favipiravir with $\mathrm{M}^{\text {pro }}$ (cavity4; binding affinity, $5.7 \mathrm{kcal} / \mathrm{mol})$.
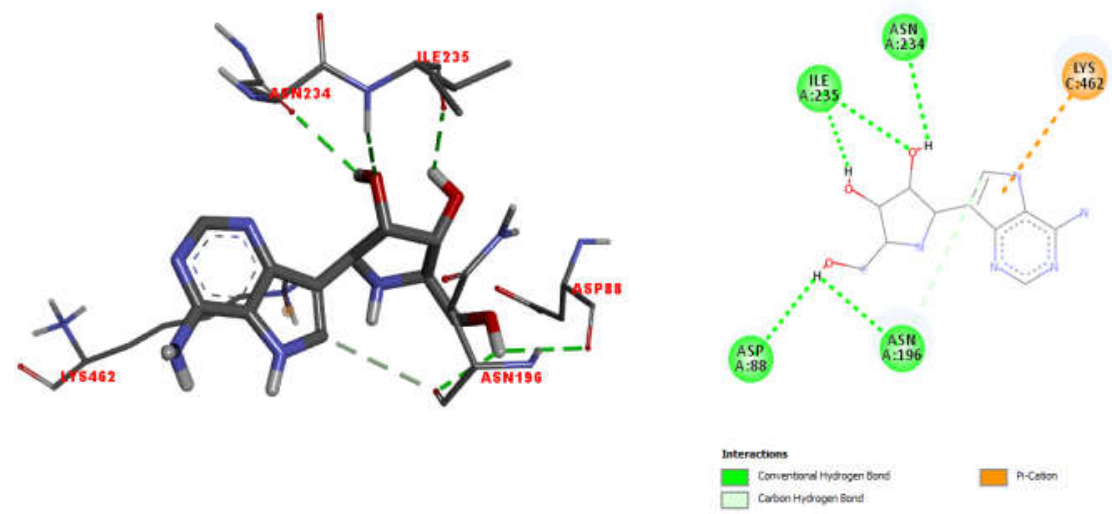

Figure 5. 2-D Molecular docked structure of galidesivir with Spike glycoprotein. Doted lines present the interactions of galidesivir with spike glycoprotein (cavity5; binding affinity, $-7.1 \mathrm{kcal} / \mathrm{mol})$.
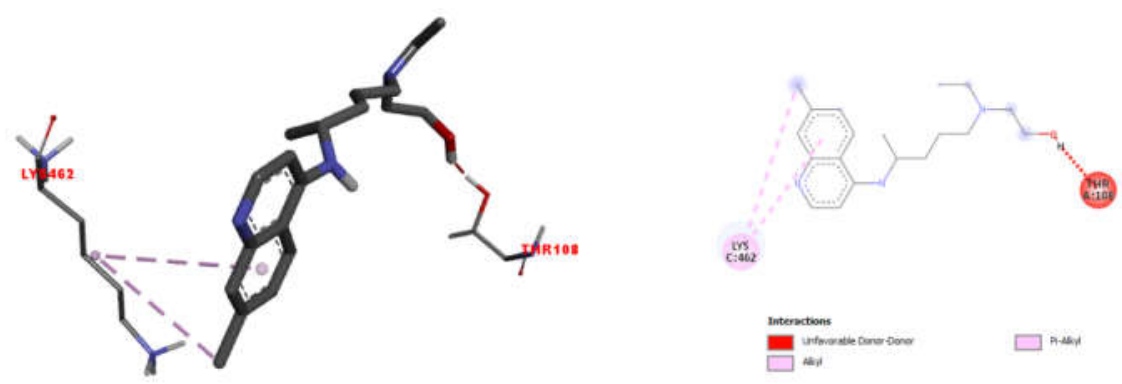

Figure 6.2-D molecular docked structure of hydroxychloroquine with Spike glycoprotein. Doted lines present the interactions of hydroxychloroquine with spike glycoprotein (cavity5; binding affinity, $-6.4 \mathrm{kcal} / \mathrm{mol}$ ). 

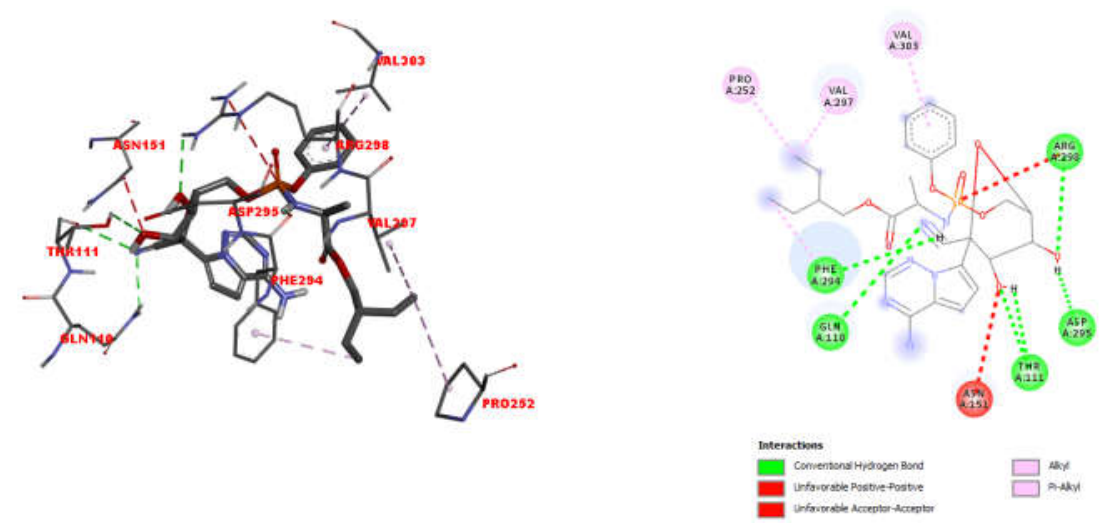

Figure 7. 2-D molecular docked structure of remdesivir with the apo form of COVID-19 $\mathrm{M}^{\text {pro }}$. Doted lines show the interactions of remdesivir with $\mathrm{M}^{\text {pro }}$. (cavity3; binding affinity $-7.7 \mathrm{kcal} / \mathrm{mol})$.

The favipiravir showed a better binding affinity for the holo form of COVID-19 $\mathrm{M}^{\text {pro }}$ (-5.7 $\mathrm{kcal} / \mathrm{mol})$ than the apo form $(-5.3 \mathrm{kcal} / \mathrm{mol})$ and the spike glycoprotein $(-5.1 \mathrm{kcal} / \mathrm{mol})$. The favipiravir interacts with the holo form of COVID-19 $\mathrm{M}^{\text {pro }}$ through H-bonds (see Figure 4). $\AA$ long hydrogen bond interaction between the molecule and the Asn151 amino acid; $2.08 \AA$ long hydrogen bond interaction with Thr292 amino acid; $2.26 \AA$ long hydrogen bond interaction with Asp295 amino acid are revealed. In the molecular docking analysis of some antiviral compounds against holo form of COVID-19 $\mathrm{M}^{\text {pro }}$ (6LU7), it has been revealed that the antiviral compounds niclosamide $\left(\mathrm{C}_{13} \mathrm{H}_{8} \mathrm{Cl}_{2} \mathrm{~N}_{2} \mathrm{O}_{4}\right)$, +(-)epicatechin $\left(\mathrm{C}_{15} \mathrm{H}_{14} \mathrm{O}_{6}\right)$, diterpene $\left(\mathrm{C}_{21} \mathrm{H}_{28} \mathrm{O}_{7}\right)$, niclosamide $\left(\mathrm{C}_{13} \mathrm{H}_{8} \mathrm{Cl}_{2} \mathrm{~N}_{2} \mathrm{O}_{4}\right)$ \}interact with the Asn151, Thr292 and Asp295 amino acid residues of the holo form of $\mathrm{M}^{\text {pro }}$ (6LU7), which are the same amino acid residues that favipiravir interacts [28].

The binding affinity of the galidesivir to the spike glycoprotein $(-7.1 \mathrm{kcal} / \mathrm{mol})$ is better than the binding affinity to the apo $(-6.4 \mathrm{kcal} / \mathrm{mol})$ and holo $(-6.2 \mathrm{kcal} / \mathrm{mol})$ forms of COVID-19 $\mathrm{M}^{\mathrm{pro}}$. The molecular docking study of galidesivir with spike resulted in H-bonding interactions between the drug and spike glycoprotein residues as follows (see Figure 5): $3.09 \AA$ long hydrogen bond interaction with the Asp88 amino acid; $2.49 \AA$ long hydrogen bond and $3.59 \AA$ long carbon hydrogen bond interactions with the Asn196 amino acid; $2.65 \AA$ long hydrogen bond interaction with the Asn234 amino acid; 2.54 and $2.21 \AA$ long hydrogen bond interaction with the Ile235 amino acid and $4.94 \AA$ long pi-cation interaction with the Lys 462 amino acid. In a recent study molecular simulation analyses of SARS-CoV-2 spike protein with phytoconstituents of Withania somnifera Dunal Habit (including Viscosalactone B) which are known to have various bioactivities, were performed [29] and is shown that viscosalactone $\mathrm{B}$ $\left(\mathrm{C}_{28} \mathrm{H}_{40} \mathrm{O}_{7}\right)$ molecule interacts with Asp88, Asn196, Asn234 and Ile235 residues of the spike glycoprotein. These are the same amino acid residues of the spike glycoprotein that galidesivir interacts with. The results indicate that the binding active site within spike glycoprotein for viscosalactone $\mathrm{B}$ molecule is the same as the galidesivir molecule we studied.

The interactions of the hydroxychloroquine molecule with spike glycoprotein are as follows (see Figure 6): $1.45 \AA$ long unfavorable donor-donor interaction between the Thr108 amino acid of the target protein and hydroxychloroquine; $5.33 \AA$ long and $5.09 \AA$ long pi-alkyl interactions between the Lys 462 residue and the drug. The hydroxychloroquine shows better binding affinity for the spike glycoprotein $(-6.4 \mathrm{kcal} / \mathrm{mol})$ than those for the apo $(-5.9 \mathrm{kcal} / \mathrm{mol})$ and holo $(-5.2$ $\mathrm{kcal} / \mathrm{mol}$ ) forms of COVID-19 $\mathrm{M}^{\mathrm{pro}}$. 
The molecular docking studies of the remdesivir molecule with Apo form of COVID-19 $\mathrm{M}^{\text {pro }}$ yielded the following interactions between remdesivir molecule and the aminoacid residues of target protein (see Figure 7): $2.92 \AA$ long hydrogen bond interaction with the Gln 110 residue; 2.83 and $3.07 \AA$ long hydrogen bond interactions with the Thr111 amino acid residue; $2.90 \AA$ long unfavorable acceptor-acceptor interaction between the Asn 151 amino acid residue; $4.85 \AA$ long alkyl interaction between the Pro252 residue; $4.70 \AA$ long Pi-Alkyl interaction and $2.52 \AA$ long hydrogen bond interaction with the Phe294 residue; $2.20 \AA$ long hydrogen bond interaction with the Asp295 residue; $4.19 \AA$ long Alkyl interaction with the Val297 residue; $4.86 \AA$ long unfavorable positive-positive interaction and $2.77 \AA$ long; hydrogen bond interaction with the Arg298 residue; $4.47 \AA$ long pi-alkyl interaction with the Val303 amino acid residue. The remdesivir shows better binding affinity for the apo form of $\mathrm{M}^{\mathrm{pro}},(-7.7 \mathrm{kcal} / \mathrm{mol})$ than for the holo $(-6.6 \mathrm{kcal} / \mathrm{mol})$ form and spike glycoprotein $(-5.7 \mathrm{kcal} / \mathrm{mol})$.

Molecular mechanical energies combined with Poisson-Boltzmann or generalized Born and surface area continuous solving (MM/PBSA and MM/GBSA) methods are approaches used to estimate the free energy of binding small ligands to biological macromolecules. Typically they are based on molecular dynamics simulations of the receptor-ligand complex. These approaches are used to estimate the free energy of binding small ligands to biological macromolecules [17$21,30]$. Typically they are based on molecular dynamics simulations of the receptor-ligand complex.

Due to the importance of MM/PBSA and MM/GBSA approaches, the binding free energies were calculated using two different programs, 1) a program developed by Wang [17], which is based on MM/PB(GB)SA approach and 2) ACFIS (ACFIS 2.0) a computer-aided fragmentbased drug discovery (FBDD) web server [18-21].

The predicted binding free energy of the arbidol-Apo form, dexamethasone-Apo form and remdesivir-Apo form were $-17.71,-31.89$ and $-3.87 \mathrm{kcal} / \mathrm{mol}$, respectively by using the $\mathrm{MM} / \mathrm{PB}(\mathrm{GB}) \mathrm{SA}$ approaches with the GAFF2 and ff14SB force field combination and the GB6 procedure [17]. We could not perform the calculations for all studied molecules due to the insufficiency of the program, which was designed for limited size receptors.

Secondly the free energy of the binding of the investigated molecules to COVID-19 $\mathrm{M}^{\text {pro }}$ and spike glycoprotein $(\Delta \mathrm{G})$ were calculated both with MM/PBSA $\{\Delta \mathrm{G}(\mathrm{PB})\}$ and MM/GBSA $\{\triangle \mathrm{G}(\mathrm{GB})\}$ methods using ACFIS 2.0 web server [18-21] and the estimated binding free energies $\{\Delta \mathrm{G}(\mathrm{PB})$ and $\Delta \mathrm{G}(\mathrm{GB})\}$ of the drug-protein system are as follows:

$$
\begin{aligned}
& \text { Arbidol-Apo form: } \Delta \mathrm{G}(\mathrm{PB})=-12.78 \mathrm{kcal} / \mathrm{mol} ; \Delta \mathrm{G}(\mathrm{GB})=-20.93 \mathrm{kcal} / \mathrm{mol} \\
& \text { Dexamethasone-Apo form: } \Delta \mathrm{G}(\mathrm{PB})=-11.55 \mathrm{kcal} / \mathrm{mol} ; \Delta \mathrm{G}(\mathrm{GB})=-16.92 \mathrm{kcal} / \mathrm{mol} \\
& \text { Remdesivir-Apo form: } \Delta \mathrm{G}(\mathrm{PB})=-20.61 \mathrm{kcal} / \mathrm{mol} ; \Delta \mathrm{G}(\mathrm{GB})=-30.09 \mathrm{kcal} / \mathrm{mol} \\
& \text { Favipiravir-Holo form: } \Delta \mathrm{G}(\mathrm{PB})=-4.79 \mathrm{kcal} / \mathrm{mol} ; \Delta \mathrm{G}(\mathrm{GB})=-7.82 \mathrm{kcal} / \mathrm{mol} \\
& \text { Colchicine- spike protein: } \Delta \mathrm{G}(\mathrm{PB})=-1.74 \mathrm{kcal} / \mathrm{mol} ; \Delta \mathrm{G}(\mathrm{GB})=-14.34 \mathrm{kcal} / \mathrm{mol} \\
& \text { Galidesivir-spike protein: } \Delta \mathrm{G}(\mathrm{PB})=6.13 \mathrm{kcal} / \mathrm{mol} ; \Delta \mathrm{G}(\mathrm{GB})=8.89 \mathrm{kcal} / \mathrm{mol}
\end{aligned}
$$$$
\text { Hidroksiklorokin- spike protein } \Delta \mathrm{G}(\mathrm{PB})=-5.53 \mathrm{kcal} / \mathrm{mol} ; \Delta \mathrm{G}(\mathrm{GB})=-9.21 \mathrm{kcal} / \mathrm{mol} \text {. }
$$

\section{CONCLUSION}

We performed an in silico molecular docking simulations on the interaction of 7 FDA approved drugs with both apo and holo forms of the $\mathrm{M}^{\text {pro }}$ enzyme of SARS-CoV-2. Moreover, the interactions of these 7 drug molecules with Spike glycoprotein protein were also investigated. The cavityplus program were used to determine the druggable cavities of the both apo and holo forms of the COVID-19 $\mathrm{M}^{\text {pro }} \mathrm{s}$ and the spike glycoprotein of the SARSCoV-2 receptors. By 
comparing all the compounds that interacted with COVID-19 $\mathrm{M}^{\text {pro }}$ based on the binding affinity, dexamethasone $(-8.6 \mathrm{kcal} / \mathrm{mol})$ followed by remdesivir $(-7.7 \mathrm{kcal} / \mathrm{mol})$ and galidesivir $(-7.1$ $\mathrm{kcal} / \mathrm{mol}$ ) have a good binding affinity. Moreover, galidesivir has been shown to have the best binding affinity for the Spike glycoprotein $(-7.1 \mathrm{kcal} / \mathrm{mol})$ among the studied compounds. In addition a set of molecular mechanics (MM) Poisson-Boltzmann (PB) surface area (SA) calculations on the investigated drugs and apo form of COVID-19 $\mathrm{M}^{\text {pro }}$ were also performed. By comparing all the compounds that interacted with COVID-19 $\mathrm{M}^{\text {pro }}$ based on the binding free energy, remdesivir showed the best interaction with the apo form of the $\mathrm{M}^{\text {pro }}\{\Delta \mathrm{G}(\mathrm{PB}):-20.61$ $\mathrm{kcal} / \mathrm{mol} ; \Delta \mathrm{G}(\mathrm{GB}):-30.09 \mathrm{kcal} / \mathrm{mol}\}$. All interactions between receptors and molecules and their binding affinities are explained in detail, these results are thought to be important for the treatment of COVID-19.

\section{ACKNOWLEDGEMENTS}

This work was supported by the Scientific Research Projects Coordination Unit of Istanbul University [ÖNAP-2423].

\section{REFERENCES}

1. Dhama, K.; Sharun, K.; Tiwari, R.; Dadar, M.; Malik, Y.S.; Singh, K.P.; Chaicumpa, W. COVID-19, an emerging corona virus infection: advances and prospects in designing and developing vaccines, immunotherapeutics, and therapeutics. Hum. Vaccin. Immunother. 2020, 16, 1232-1238.

2. Zhu, N.; Zhang, D.; Wang, W.; Li, X.; Yang, B.; Song, J.; Zhao, X.; Huang, B.; Shi, W.; Lu, R.; Niu, P.; Zhan, F.; Ma, X.; Wang, D.; Xu, W.; Wu, G.; Gao, G.; Tan, W. A novel corona virus from patients with pneumonia in China, 2019. New Engl. J. Med. 2020, 382, 727-733.

3. Yang, P.; Wang, X. COVID-19: A new challenge for human beings. Cell. Mol. Immunol. 2020, 17, 555-557.

4. Yao, X.; Ye, F.; Zhang, M.; Cui, C.; Huang, B.; Niu, P.; Liu, X.; Zhao, L.; Dong, E.; Song, C.; Zhan, S.; Lu, R.; Li, H.; Tan, W.; Liu, D. In vitro antiviral activity and projection of optimized dosing design of hydroxychloroquine for the treatment of severe acute respiratory syndrome corona virus 2 (SARS-CoV-2). Clin.l Infect. Dis. 2020, 71, 732-739.

5. Wang, M.; Cao, R.; Zhang, L.; Yang, X.; Liu, J.; Xu, M.; Shi, Z.; Hu, Z.; Zhong, W.; Xiao, G. Remdesivir and chloroquine effectively inhibit the recently emerged novel corona virus (2019-nCoV) in vitro. Cell Res. 2020, 30, 269-271.

6. Lu, R.; Zhao, X.; Li, J.; Niu, P.; Yang, B.; Wu, H.; Wang, W.; Song, H.; Huang, B.; Zhu, N.; Bi, Y.; Ma, X.; Zhan, F.; Wang, L.; Hu, T.; Zhou, H.; Hu, Z.; Zhou, W.; Zhao, L.; Chen, J.; Meng, Y.; Wang, J.; Lin, Y.; Yuan, J.; Xie, Z.; Ma, J.; Li, W.; Wang, D.; Xu, W.; Holmes, E.; Gao, G.; Wu, G.; Chen, W.; Shi, W.; Tan, W. Genomic characterisation and epidemiology of 2019 novel corona virus: Implications for virus origins and receptor binding. Lancet 2020, 395, 565-574.

7. Mohapatra, R.K.; Pintilie, L.; Kandi, V.; Sarangi, A.K.; Das, D.; Sahu, R.; Perekhoda, L. The recent challenges of highly contagious COVID-19; causing respiratory infections: Symptoms, diagnosis, transmission, possible vaccines, animal models and immunotherapy. Chem. Biol. Drug Design 2020, 96, 1187-1208.

8. Abdel-Maksoud, K.; al-Badri, M.A.; Lorenz, C., Essex, J.W. Allosteric regulation of SARSCoV-2 protease: Towards informed structure-based drug discovery. ChemRxiv 2020. DOI: 10.26434/chemrxiv.12967655.v2.

9. Amin, M.; Abbas, G. Docking study of chloroquine and hydroxychloroquine interaction with SARS-CoV-2 spike glycoprotein-An in silico insight into the comparative efficacy of repurposing antiviral drugs.J. Biomol. Struc. Dynamics 2020, 1-11. DOI: 10.1080/07391102.2020.1775703. 
10. Rachakulla, V.; Rachakulla, H. Potential docking affinity of three approved drugs against SARS-CoV-2 for COVID-19 treatment. ChemRxiv 2020. DOI: 10.26434/chemrxiv.12548063.v1.

11. Khan, S.U.; Htar, T. Deciphering the binding mechanism of dexamethasone against SARSCoV-2 Main Protease: Computational molecular modelling approach. ChemRxiv Preprint 2020. DOI: 10.26434/chemrxiv.12517535.v1.

12. Blaising, J.; Polyak, S.J.; Pecheur, E.I. Arbidol as a broad-spectrum antiviral: An update. Antiviral Res. 2014, 107, 84-94.

13. Shao, Y.; Molnar, L.F.; Jung, Y.; Kussmann, J.; Ochsenfeld, C.; Brown, S.T.; Gilbert, A.T.B.; Slipchenko, L.V.; Levchenko, S.V.; O’Neill, D.P.; DiStasio, R.A.; Lochan, R.C.; Wang, T.; Beran, G.J.O; Besley, N.A.; Herbert, J.M.; Lin, C.Y.; Voorhis, T.V.; Chien, S.H.; Sodt, A.; Steele, R.P.; Rassolov, V.A.; Maslen, P.E.; Korambath, P.P.; Adamson, R.D.; Austin, B.; Baker, J.; Byrd, E.F.C.; Dachsel, H.; Doerksen, R.J.; Dreuw, A.; Dunietz, B.D.; Dutoi, A.D.; Furlani, T.R.; Gwaltney, S.R.; Heyden, A.; Hirata, S.; Hsu, C.P.; Kedziora, G.; Khalliulin, R.Z.; Klunzinger, P.; Lee, A.M.; Lee M.S.; Liang, W.; Lotan, I.; Nair, N.; Peters, B.; Proynov, E.I.; Pieniazek, P.A.; Rhee, Y.M.; Ritchie, J.; Rosta, E.; Sherrill, C.D.; Simmonett, A.C.; Subotnik, J.E.; Woodcock, H.L.; Zhang, W.; Bell, A.T.; Chakraborty, A.K.; Chipman, D.M.; Keil F.J.; Warshel, A.; Hehre, W.J.; Schaefer, H.F.; Kong, J.; Krylov, A.I.; Gilla, P.M.W.; Head-Gordon, M. Advances in methods and algorithms in a modern quantum chemistry program package. Phys. Chem. Chem. Phys. 2006, 8, 31723191.

14. Devar, M.J.S.; Zoebisch, E.G.; Healy, E.F.; Stewart, J.J.P. AM1: A new General purpose quantum mechanical molecular model. J. Am. Chem. Soc. 1985, 107, 3902-3909.

15. Xu, Y.; Wang, S.; Hu, Q.; Gao, S.; Ma, X.; Zhang, W.; Shen, Y.; Chen, F.; Lai, L.; Pei, J. CavityPlus: A web server for protein cavity detection with pharmacophore modelling, allosteric site identification and covalent ligand binding ability prediction. Nucl. Acids Res. 2018, 46, W374-W379.

16. Trott, O.; Olson, A.J. AutoDock Vina: Improving the speed and accuracy of docking with a new scoring function, efficient optimization, and multithreading. J. Comput. Chem. 2010, 31, 455-461.

17. Wang, Z.; Wang, X.; Li, Y.; Lei, T.; Wang, E.; Li, D.; Kang, Y.; Zhu, F.; Hou, T. farPPI: A web server for accurate prediction of protein-ligand binding structures for small-molecule PPI inhibitors by MM/PB (GB) SA methods. Bioinformatics 2019, 35, 1777-1779.

18. Hao, G.F.; Jiang, W.; Ye, Y.N.; Wu, F.X.; Zhu, X.L.; Guo, F.B.; Yang, G.F. ACFIS: A web server for fragment-based drug discovery. Nucl. Acids Res. 2016, 44, W550-W556.

19. Hao, G.F.; Wang, F.; Li, H.; Zhu, X.L.; Yang, W.C.; Huang, L.S.; Wu, J.; Berry, E.A.; Yang, G.F. Computational discovery of picomolar $\mathrm{Q}_{0}$ site inhibitors of cytochrome $\mathrm{bc}_{1}$ complex. J. Am. Chem. Soc. 2012, 134, 11168-11176.

20. Yang, J.F.; Wang, F.; Jiang, W.; Zhou, G.Y.; Li, C.Z.; Zhu, X.L.; Hao, G.; Yang, G.F. PADFrag: A database built for the exploration of bioactive fragment space for drug discovery. J. Chem. Inf. Model. 2018, 58, 1725-1730.

21. Cheron, N.; Jasty, N.; Shakhnovich, E.I. OpenGrowth: An automated and rational algorithm for finding new protein ligands. J. Med. Chem. 2016, 59, 4171-4188.

22. Belouzard, S.; Millet, J.K.; Licitra, B.N.; Whittaker, G.R. Mechanisms of corona virus cell entry mediated by the viral spike protein. Viruses 2012, 4, 1011-1033.

23. Zhang, B.; Zhao, Y.; Jin, Z.; Liu, X.; Yang, H.; Rao, Z. The crystal structure of COVID-19 main protease in apo form. Published Online 2020. DOI: 10.2210/pdb6M03/pdb.

24. Jin, Z.; Du, X.; Xu, Y.; Deng, Y.; Liu, M.; Zhao, Y.; Zhang, B.; Li, X.; Zhang, L.; Peng, C.; Duan, Y.; Yu, J.; Wang, L.; Yang, K.; Liu, F.; Jiang, R.; Yang, X.; You, T.; Liu, X.; Yang, X.; Bai, F.; Liu, H.; Liu, X.; Guddat, L.W.; Xu, W.; Xiao, G.; Qin, C.; Shi, Z.; Jiang, H.; 
Rao, Z.; Yang, H. Structure of mprofrom SARS-CoV-2 and discovery of its inhibitors. Nature 2020, 582, 289-293.

25. Walls, A.C.; Park, Y.J.; Tortorici, M.A.; Wall, A.; McGuire, A.T.; Veesler, D. Structure, function, and antigenicity of the SARS-CoV-2 spike glycoprotein. Cell 2020, 181, 281-292.

26. Singh, S.; Florez, H. Bioinformatic study to discover natural molecules with activity against COVID-19. F1000Res. 2020, 9, 1203. DOI: 10.12688/f1000research.26731.1.

27. Souza, P.F.; Lopes, F.E.; Amaral, J.L.; Freitas, C.D.; Oliveira, J.T. A molecular docking study revealed that synthetic peptides induced conformational changes in the structure of SARS-CoV-2 spike glycoprotein, disrupting the interaction with human ACE2 receptor. Int. J. Biol. Macromol. 2020, 164, 66-76.

28. Kumar, D.; Chandel, V.; Raj, S.; Rathi, B. In silico identification of potent FDA approved drugs against corona virus COVID-19 main protease: A drug repurposing approach. Chem. Biol. Lett. 2020, 7, 166-175.

29. Srivastava, A.; Siddiqui, S.; Ahmad, R.; Mehrotra, S.; Ahmad, B.; Srivastava, A.N. Exploring nature's bounty: identification of Withania somnifera as a promising source of therapeutic agents against COVID-19 by virtual screening and in silico evaluation. $J$. Biomol. Struct. Dynamics 2020, 1-51. DOI: 10.1080/07391102.2020.1835725.

30. Wang, E.; Sun, H.; Wang, J.; Wang, Z.; Liu, H.; Zhang, J.Z.H.; Hou, T. End-point binding free energy calculation with MM/PBSA and MM/GBSA: Strategies and applications in drug design. Chem. Rev. 2019, 119, 9478-9508. 